\title{
sciendo FORECASTS OF SIZE OF STEEL PRODUCTION IN POLAND UNTIL 2022
}

doi:10.2478/mape-2018-0063

Date of submission of the article to the Editor: 03/2018

Date of acceptance of the article by the Editor: 07/2018
MAPE 2018, volume 1, issue 1, pp. 499-505

\section{Dr Bożena Gajdzik \\ Silesian University of Technology, Poland}

\begin{abstract}
The article presents the results of forecasting the volume (size) of steel production in Poland based on selected adaptation models. The data used in forecasting were the annual size of steel production in the period from 2000 to 2017. Data on the size of steel production in Poland were obtained from reports of both the Polish Steel Association in Katowice (Poland) and the World Steel Association. The accuracy of predictions was determined by the values of real deviation of forecasted variable from forecasts (extinguished - ex post) using square root calculated from mean square error of apparent forecasts, ie RMSE - Root Mean Square Error and mean value of relative error of expired forecasts $\Psi$. Forecasts can be used in making decisions in metallurgical enterprises for building production scenarios.
\end{abstract}

Keywords: steel production, forecasts, adaptation models

\section{INTRODUCTION}

In the recent history of metallurgy in Poland (the last two decades), important developments in the steel sector include: the creation of enterprises with foreign capital having a significant share in the steel market in Poland (Gajdzik and Sroka 2012), large capital expenditures on technological innovations in steel mills and withdrawal of unprofitable steel melting technology (the Martin furnace) (Gajdzik, 2013a), as well as the implementation of the latest computerassisted BAT technology, accompanied by changes in the organization of work (implementation of methods and tools to improve the process of enterprise management and production control). Metallurgical enterprises have introduced global steel production standards (WCM) (Gajdzik, 2013b), and individual products have obtained certificates required on the global steel market (in accordance with the expectations of individual segments of the steel recipients market). The aforementioned factors have made the situation of the steel sector in Poland stable in recent years. The steel sector in the country is one of the important industries. Its share in the sold production of industry accounts for approx. $2.5 \%$. Steel is the basic building material used in construction (about $45 \%$ of national steel consumption is attributable to the construction sector with an average annual consumption of approx. 13 million tons) (Polish Steel Association, 2017). Significant share in steel consumption is also played by sectors: manufacture of metal products (about 15\%), manufacture of machinery and equipment (about 10\%), automotive and transport equipment (about 15\%), household appliances (slightly more than 5\%), pipe production (less than 10\%).

The problem of research was: how will the steel production change in Poland in the coming years, assuming that radical changes in the sector will not occur.

Contents of the work: this paper presents forecasts of steel production volume in Poland developed on the basis of selected adaptation models. The publication includes forecasts regarding the volume of steel production in Poland until 2022.

Application of research results: forecasting is a valuable tool informing about the future, and the prepared forecasts can be used by economic entities (metallurgical plants) to make decisions in the next years' perspective and to build production scenarios. 


\section{METHODOLOGY OF RESEARCH}

Steel models were used to predict the size of steel production. These models are characterized by high flexibility and ability to adapt to irregular changes in the direction of the trend, as well as possible distortions of seasonal variations. The class of adaptive models is quite wide (Armstrong, 2001). The following forecasting methods based on adaptive models were used in the research process (Krawiec, 2014): naive methods, moving average methods (simple and weighted), exponential smoothing models (Brown and Holt, 1963) and exponential-self-guiding models. In order to assess the acceptability of presented forecasting methods and to choose the most accurate, an evaluation of two most common ex post forecast errors have been performed:

- Root Mean Square Error (RMSE) - which informs about average deviations of forecasts from empirical values in frames of the forecast verification interval; calculated by Equation 1:

$$
R M S E=\sqrt{\frac{1}{n-m} \sum_{t=m+1}^{n}\left(y_{t}-y_{t}^{*}\right)^{2}}
$$

- the mean relative ex post forecast error - which informs about the share of absolute error per unit of real value of variable $y_{t}$ and is calculated by Equation 2:

$$
\Psi=\frac{1}{n-m} \sum_{t=m+1}^{n} \frac{\left|y_{t}-y_{t}^{*}\right|}{y_{t}}
$$

In Equations $1 \& 2 y_{t}$ is an empirical value, i.e. realization of variable $y$ in a $t$ period of time $t(t \in \overline{1, T}) ; y_{t}^{*}$ is the forecast value; $n$ is the number of elements of the time series; $m$ is the number of initial time moments $t$, for which ex post forecast has not been calculated or is being treated as a part of necessary startup mechanism (Manikowski \& Tarapata, 2002). The onedimensional time series used to determine the forecasts of the volume of steel production in Poland is the production of steel (million tons) a year. (Table 1).

Table 1

Steel production in Poland in 2000-2017 (mln tons)

\begin{tabular}{|c|c|c|c|c|c|}
\hline No. & Year & Production & No. & Year & Production \\
\hline 1 & 2000 & 10.50 & 10 & 2009 & 7.13 \\
\hline 2 & 2001 & 8.81 & 11 & 2010 & 7.99 \\
\hline 3 & 2002 & 8.37 & 12 & 2011 & 8.78 \\
\hline 4 & 2003 & 9.11 & 13 & 2012 & 8.35 \\
\hline 5 & 2004 & 10.58 & 14 & 2013 & 7.95 \\
\hline 6 & 2005 & 8.34 & 15 & 2014 & 8.56 \\
\hline 7 & 2006 & 9.99 & 16 & 2015 & 9.20 \\
\hline 8 & 2007 & 10.63 & 17 & 2016 & 8.99 \\
\hline 9 & 2008 & 9.73 & 18 & 2017 & 10.33 \\
\hline
\end{tabular}

Source: (Polish Steel Association, World Steel Association - yearbooks).

The empirical (real) values used for forecasting are shown in Fig. 1. The production volume was presented on the abscissa axis (Figure 1$)$ and subsequent years $(t=2000,2001, \ldots 2017)$ on the ordinate axis (Fig. 1). 


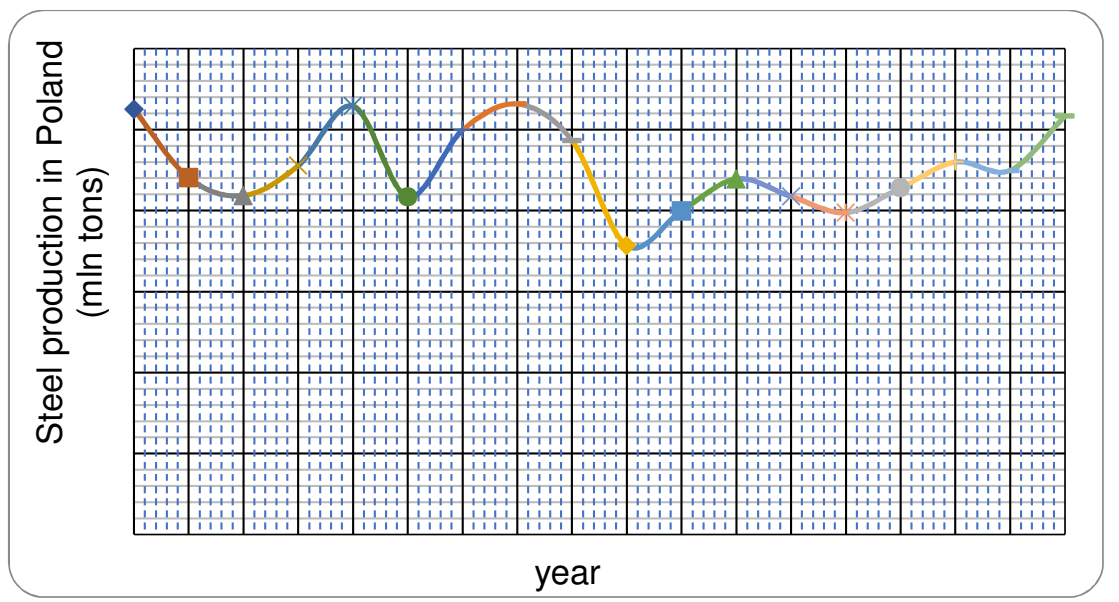

Fig. 1. Steel production in Poland in 2000-2017

On the basis of visual assessment of the chart made, the basic chronological decomposition of the time series was made, determining the lack of a one-way change in the volume of steel production (no obvious growing or decreasing trend). The value of empirical data oscillates around the average value - the average annual volume of steel production in Poland -9.074 million tons of steel. For the purposes of research (forecasting), however, it was assumed that there could be an additive or multiplicative development trend. In the course of the trend of the phenomenon studied - steel production quantities - no fluctuations were observed, which would be cyclical - seasonal - repeatable at a given time. In the course of the examined phenomenon there are periodic fluctuations caused by the economic situation (increase or decrease in demand on the global steel market).

\section{RESULTS OF RESEARCH}

The obtained forecasts are presented in table 2, and their interpretation was made according to the order of forecasting methods used.

Table 2

Forecasts of steel production in Poland in 2018-2022

\begin{tabular}{|l|l|c|c|c|c|c|c|c|}
\hline No. & \multicolumn{1}{|c|}{ Method/model } & $\mathbf{2 0 1 8}$ & $\mathbf{2 0 1 9}$ & $\mathbf{2 0 2 0}$ & $\mathbf{2 0 2 1}$ & $\mathbf{2 0 2 2}$ & $\mathbf{R M S E}$ & $\mathbf{\Psi}$ \\
\hline 1 & Additive naive method (point forecast) & 9.202 & - & - & - & - & 1.232 & 0.118 \\
\hline 2 & $\begin{array}{l}\text { Multiplicative naive method with } \\
\text { increasing tendency }\end{array}$ & 11.857 & 13.609 & 15.620 & 17.928 & 20.577 & 1.785 & 0.159 \\
\hline 3 & $\begin{array}{l}\text { Simple moving average for time series } \\
\text { with constant k-point value } k=2\end{array}$ & 9.665 & 9.998 & 9.831 & 9.914 & 9.873 & 1.233 & 0.113 \\
\hline 4 & $\begin{array}{l}\text { Simple moving average for time series } \\
\text { with constant k-point value } k=3\end{array}$ & 9.511 & 9.614 & 9.818 & 9.647 & 9.692 & 1.145 & 0.100 \\
\hline 5 & $\begin{array}{l}\text { Weighted moving average for time series } \\
\text { with constant k-point value } k=3 \text { ( } w_{1}=0.10 ; \\
\left.w_{2}=0.20 ; w_{3}=0.70\right)\end{array}$ & 9.951 & 9.932 & 9.976 & 9.964 & 9.963 & 1.143 & 0.099 \\
\hline 6 & $\begin{array}{l}\text { Simple moving average for increasing } \\
\text { time series with k-point } k=2\end{array}$ & 10.894 & 11.841 & 12.595 & 13.447 & 14.251 & 1.756 & 0.179 \\
\hline 7 & $\begin{array}{l}\text { Simple moving average for increasing } \\
\text { time series with k-point } k=3\end{array}$ & 10.921 & 11.493 & 12.324 & 12.989 & 13.679 & 1.552 & 0.148 \\
\hline 8 & $\begin{array}{l}\text { Simple moving average for increasing } \\
\text { time series with k-point } k=3\left(w_{1}=0.20 ;\right. \\
\left.w_{2}=0.30 ; w_{3}=0.50\right)\end{array}$ & 11.330 & 12.257 & 13.645 & 15.383 & 17.332 & 1.603 & 0.155 \\
\hline 9 & $\begin{array}{l}\text { Simple exponential smoothing for } \\
\mathrm{y}^{*}=\mathrm{y}_{1}(\alpha \text { opt.=0.3993) }\end{array}$ & 9.428 & 9.428 & 9.428 & 9.428 & 9.428 & 1.118 & 0.100 \\
\hline 10 & $\begin{array}{l}\text { Simple exponential smoothing for } y_{1}^{*} \\
\text { equal to the average of first } 6 \text { empirical } \\
\text { data } \alpha \text { opt.=0.2592) }\end{array}$ & 9.170 & 9.170 & 9.170 & 9.170 & 9.170 & 1.064 & 0.095 \\
\hline
\end{tabular}




\begin{tabular}{|c|c|c|c|c|c|c|c|c|}
\hline 11 & $\begin{array}{l}\text { Simple single exponential smoothing } \\
\text { (Brown's model) ( } \alpha \text { opt. }=0.2774 \text { ) }\end{array}$ & 9.637 & 9.444 & 9.391 & 9.376 & 9.372 & 1.078 & 0.096 \\
\hline 12 & $\begin{array}{l}\text { Exponential autoregressive model for } \\
k=3, l=2\left(\alpha \text { opt. }=0.1563 ; \beta_{1}=0.7 ; \beta_{2}=0.2\right. \\
\left.\beta_{3}=0.1 ; \delta_{1}=0.8 ; \delta_{2}=0.2\right)\end{array}$ & 9.201 & 9.004 & 8.961 & 8.977 & 8.977 & 1.096 & 0.099 \\
\hline 13 & $\begin{array}{l}\text { Exponential autoregressive model for } \\
k=2, l=2\left(\alpha \text { opt }=0.1937 ; \beta_{1}=0.7 ; \beta_{2}=0.3 \text {; }\right. \\
\left.\beta_{3}=0.1 ; \delta_{1}=0.8 ; \delta_{2}=0.2\right)\end{array}$ & 9.425 & 9.120 & 9.094 & 9.084 & 9.084 & 1.040 & 0.089 \\
\hline 14 & $\begin{array}{l}\text { Holt's linear trend model with additive } \\
\text { trend for } S_{1}=y_{2}-y_{1} \\
\text { (aopt. }=0.9221 ; \beta o p t=0.2774 \text { ) }\end{array}$ & 10.639 & 11.043 & 11.446 & 111.850 & 12.253 & 1.446 & 0.137 \\
\hline 15 & $\begin{array}{l}\text { Holt's linear trend model with additive } \\
\text { trend for } S_{1}=0 \text { ( } \alpha \text { opt. }=0.3991 ; \\
\beta \text { opt }=0.0001)\end{array}$ & 9.427 & 9.427 & 9.427 & 9.427 & 9.426 & 1.150 & 0.106 \\
\hline 16 & $\begin{array}{l}\text { Holt's linear trend model with } \\
\text { multiplicative trend for } S_{1}=y_{2} / y_{1} \\
\text { ( } \alpha \text { opt. }=0.9507 ; \beta \text { opt }=0.2076 \text { ) }\end{array}$ & 10.629 & 11.003 & 11.389 & \begin{tabular}{|l|}
11.789 \\
\end{tabular} & 12.203 & 1.362 & 0.128 \\
\hline 17 & $\begin{array}{l}\text { Holt's linear trend model with } \\
\text { multiplicative trend for } S_{1}=1 \\
(\alpha \text { opt. }=0.3991 ; \beta \text { opt }=0.0001)\end{array}$ & 9.427 & 9.427 & 9.427 & 9.427 & 9.427 & 1.150 & 0.106 \\
\hline 18 & $\begin{array}{l}\text { Holt's linear trend model with additive } \\
\text { damped trend for } S_{1}=y_{2}-y_{1} \\
\text { ( } \alpha \text { opt. }=1.000 ; \beta \text { opt }=0.0001 \\
\Phi \text { opt }=0.4751 \text { ) }\end{array}$ & 10.330 & 10.330 & 10.330 & 10.330 & 10.330 & 1.188 & 0.112 \\
\hline 19 & $\begin{array}{l}\text { Holt's linear trend model with additive } \\
\text { damped trend for } S_{1}=0 \\
(\alpha \text { opt. }=1.000 ; \beta \text { opt }=0.0001 \\
\Phi \text { opt }=0.0001)\end{array}$ & 10.330 & 10.330 & 10.330 & 10.330 & 10.330 & 1.232 & 0.118 \\
\hline 20 & $\begin{array}{l}\text { Holt's linear trend model with } \\
\text { multiplicative damped trend for } S_{1}=y_{2} / y_{1} \\
(\alpha \text { opt. }=0.9507 ; \beta \text { opt }=0.2076 ; \\
\Phi \text { opt=1.000) }\end{array}$ & 10.629 & 11.003 & 11.389 & 11.789 & 12.203 & 1.362 & 0.128 \\
\hline 21 & $\begin{array}{l}\text { Holt's linear trend model with } \\
\text { multiplicative damped trend for } \\
S_{1}=1(\alpha \text { opt. }=0.3991 ; \beta \text { opt }=0.0001 \\
\Phi \text { opt=1.000) }\end{array}$ & 9.427 & 9.427 & 9.427 & 9.427 & 9.427 & 1.150 & 0.106 \\
\hline 22 & $\begin{array}{l}\text { Holt's quadratic trend model with additive } \\
\text { formula for } S_{1}=y_{2}-y_{1} \\
\text { ( } \alpha \text { opt }=0.4368 ; \beta \text { opt }=0.4516 \\
\Phi \text { opt }=0.5506)\end{array}$ & 10.411 & 11.139 & 12.040 & 13.113 & 14.358 & 1.238 & 0.108 \\
\hline 23 & $\begin{array}{l}\text { Holt's quadratic trend model with additive } \\
\text { formula for } S_{1}=0 \\
\text { ( } \alpha \text { opt. }=0.7457 ; \beta \text { opt }=0.0001 \\
\Phi \text { opt }=0.3132 \text { ) }\end{array}$ & 10.125 & 10.508 & 11.147 & 12.040 & 13.190 & 1.264 & 0.119 \\
\hline 24 & $\begin{array}{l}\text { Brown's double exponential smoothing } \\
\text { (linear) ( } \alpha \text { opt. }=0.1219 \text { ) }\end{array}$ & 8.845 & 8.806 & 8.767 & 8.727 & $8, .688$ & 1.141 & 0.106 \\
\hline 25 & $\begin{array}{l}\text { Brown's triple exponential smoothing } \\
\text { (quadratic) } \\
\text { ( } a \text { opt. }=0.0666 \text { ) }\end{array}$ & 8.666 & \begin{tabular}{|l}
8.597 \\
\end{tabular} & 8.530 & 8.464 & \begin{tabular}{|l}
8.397 \\
\end{tabular} & 1.156 & 0.108 \\
\hline 26 & $\begin{array}{l}\text { Advanced exponential autoregressive } \\
\text { model for } k=3, l=2\left(\beta_{1}=0.2 ; \beta_{2}=0.3\right. \\
\left.\beta_{3}=0.5 ; \delta_{1}=0.4 ; \delta_{2}=0.6\right)\end{array}$ & 9.009 & 9.024 & 9.040 & 9.056 & 9.071 & 0.990 & 0.096 \\
\hline \multicolumn{9}{|c|}{ ADDITIONAL MODEL } \\
\hline 27 & $\begin{array}{l}\text { Creep trend and harmonic weights } \\
\text { method }\end{array}$ & 10.541 & 10.752 & 10.986 & 11.174 & 11.385 & 0.509 & 0.043 \\
\hline
\end{tabular}

* value of the smoothing parameter (or weight): $\alpha, \beta, \Phi$ for one of the two prediction errors using Solver in Excel, the value of the parameter for which the smaller error of expired forecasts was obtained was selected. The good quality forecasts are marked in gray.

\subsection{Forecasts obtained using the naive method}

Using the naive method, a point forecast for the development trend in the additive approach was constructed (for a time series around the fixed (average) or development trend (No.1) and forecasts assuming a multiplicative trend with a development trend (No. 2). No. 1 the level of the variation coefficient $V z$ was checked, which was $<0.3$, thus it was established that there is a time series around the average value and the following formulas were used: 
- ex post forecast: $y_{t}{ }^{*}=y_{t-1}$ (for $\left.t=2 \ldots 18\right)$

- ex ante forecast: ( 2018 year) $y_{T}^{*}=y_{T-1}$ (for $T=19$ )

The application of method No.1 made it possible to obtain a point forecast for 2018, which amounted to 9.202 million tons. This forecast value slightly exceeds the level of average annual steel production in Poland (average annual production value calculated on the basis of data for 2000-2017 amounted to 9.074 million tons). In turn, the forecasts obtained using the No. 2 were unusable (low quality of forecasts), the forecasts were characterized by strong deviations compared to the current course of the studied phenomenon (no clear development trend).

\subsection{Forecasts obtained using the mobile average model}

Using the moving average models, the variable forecast for moment (or period) $t$ is the simple or weighted arithmetic mean $\left(w_{j}\right)$ of last observations from the series (Krawiec, 2014). For the forecasting of steel production in Poland, the value of $k$ (smoothing constant) equal to 2 or 3 . Models were considered for a series shaped around a constant (average) value and around a development tendency ( 6 prognostic models were obtained) - tab. 2 (models from No.3 to No.8). From among the models obtained, the best fit was shown by the No. 5 (the lowest forecast error), a relatively good prediction match was also obtained using the No. 3 and No. 4 model. The average value of the obtained ex ante forecasts was calculated, and so: for the model No. 3 it was 9.858 million tons; for model No. 4 was 9.658 million tons and for model No. 5 was 9.960 million tons. In comparison to the current average annual production of steel in Poland (9.07 million tons), the level of ex ante forecasts obtained is higher by approx. $7 \%$ or $10 \%$. Based on the results of forecasting using these methods, it can be assumed that in the coming years (period 2018-2022), the steel sector in Poland will produce more than 9.5 million tons but less 10 million tons of steel per year. In turn, the ex ante forecasts obtained on the basis of these models 6-8 were characterized by a strong growing trend. However, the time series of the studied phenomenon did not show a clear development trend. From here, it can be concluded that these forecasts are of low quality.

\subsection{Forecasts obtained using exponential smoothing models}

In this group of models, a set of forecasting methods is considered, the common feature of which is the smoothing of the dynamic series by means of a weighted average with exponentially determined weights (weights are heading exponentially to zero). For the needs of the research, a simple exponential smoothing model was used and Holt developed according to the development trend: an additive or multiplicative trend. The models of Brown are also presented, which are based on general exponential smoothing operators defined in a recursive manner (Brown, 1963). Assuming, as successive operators of the $k$-th smoothing operators, the models of single, double and triple exponential smoothing were defined (Brown model). Forecasting also uses a developed form of models using the autoregression mechanism - exponential-autoregressive models. Forecasts using the mentioned models are summarized in tab. 2. The forecasts obtained using a simple exponential smoothing model (models No. 9 and No. 10) proved to be useless due to the identical values of forecasts and difficulties in the optimization process of the a parameter. Expired forecasts received using the No. Model. 11 are well matched to the variables studied $(\Psi<10 \%)$, and the ax ante forecasts obtained on an annual average basis amount to 9.444 million tons. The trend of ex ante forecasts - decreasing in the years 2018-2022 from 9.6 to 9.4 million tons of steel. Exponentautoregressive models (models No. 12 and No.13) gave good quality forecasts with a declining trend - the average annual forecast value in the No. 12 model was 9.024 million tons (less than the annual average real steel production values in Poland in the analyzed period); 9.162 million tons. On the basis of the Holt model (Holt's linear trend model with additive trend) strong trends of increasing forecasted quantities of steel production in 2018-2022 (models No. 14 in 
table 2) were obtained with high ex post forecasts. The results of forecasting using the 15 model were also useless (identical forecast values, difficulties in the optimization of the $\alpha$ parameter). The next forecasts that should be rejected are the models: 17-19 and model 21 (repeatability of forecasted values, difficulties in determining smoothing parameters). Other forecast values calculated from the assumptions of models: 16, 20, 22-23 show a strong upward trend, even to the level of 14.4 million tons in 2022. The value of these forecasts is in the range of 10.1 million tons (model No. 22) to 14.4 million tons (model No. 21). The next category were models according to Brown's assumptions (models from 24-25): Brown's double exponential smoothing (linear) and Brown's triple exponential smoothing (quadratic). On the basis of these models, similar forecasts were obtained that did not exceed 9 million tons of steel in the individual forecasted years. Last model was advanced exponential autoregressive model for $k=3, l=2\left(\beta_{1}=0.2 ; \beta_{2}=0.3 ; \beta_{3}=0.5 ; \delta_{1}=0.4 ; \delta_{2}=0.6\right)$. Forecasts obtained on the basis of this model did not exceed the level of 10 million tons of steel produced annually in the forecasted period with the lowest forecasting errors $\psi$ and RMSE) - see tab. Pos. 26 in Tab. 2.

\section{CONCLUSION}

Based on the adaptive models used to realize forecasts of steel production volumes in Poland until 2022, it was found that good quality forecasts are obtained for forecasts (ex ante) around the average annual value of steel production in Poland, which in the years 2000-2017 amounted to 9.074 million tons. Using Holt models for development trends, a significant increase in forecasts was obtained (ex ante), exceeding in the first forecast period the level of 10 million tons of steel and in the last even reaching the level of 14.4 million tons of steel. These forecasts could be rejected were it not for the fact that in Poland currently only $75 \%$ of production capacity is used for steel production (with increasing production capacities), and in recent years steel consumption increased significantly, reaching in 2017 the level of 13.8 million tons (in Poland steel became more import than export). It can therefore be assumed that with favorable economic conditions, more steel can be produced in Poland. The downward trend of ex ante forecasts was obtained using the Brown model, forecast below the current average annual production. The lowest forecasting errors ( $\Psi$ and RMSE) were obtained for forecasts obtained by using advanced exponential autoregressive model (0.096 and 0.990 , respectively) - model No. 26 in Table 2. These annual forecasts (ex ante) slightly exceeded 9 million tons of steel. The last model (No. 27 in Table 2) is not included in the classic adaptation models, it was used to develop forecasts to look for other forecasting methods (including methods typical for trends with cyclical fluctuations and autoregressive models). Ex post forecasts using the No. 27 method are subject to the smallest errors, and the obtained ex ante forecasts oscillate around 10.5 million tons of steel produced annually in the forecasted period of 2018-2022. Obtained forecasts can be used in making decisions in metallurgical enterprises for building production scenarios. This scenario is, in a very simplistic, possible but hypothetical picture of the future. A favorable sequence of events that may occur will result in the completion of a particular scenario image of the future (Chermack et al., 2001). The task of planning is to choose among the possible trajectories of the production system that is most desirable in the light of the analysis of the demand for funds for its implementation and the means that the system can have in the given period for the purpose (Rue, Holland, 1986). The result of prognostic analysis, there are such scenarios of the future of steel production in Poland: base-case scenario: forecasting yearly steel production from 9 to 10 million tons, worst-case scenario: forecasting yearly steel production from 9 to 10 million tons less than 9 million tons, and best-case scenario: forecasting yearly steel production below 10 million tons (Gajdzik, 2017). 


\section{REFERENCES}

Armstrong, J.S. (Ed.) (2001).Principles of Forecasting - A Handbook for Researchers and Practitioners. Boston, MA, USA: Springer.

Brown, R.G. (1963). Smoothing, Forecasting and Prediction of Discrete Time Series. Englewood Cliffs, NY, USA: Prentice Hall.

Chermack, T.J., Lynham S.A. and Ruona, W. E. A. (2001). A Review of Scenario Planning Literature. Futures Research Quarterly, 17(2), pp. 7-31.

Gajdzik, B., (2017). The Predictive Scenario Analysis in a Business Model: Variants of Possible Steel Production Trajectories and Efficiency in Poland. In: Jabłoński M., ed., Strategic Performance Management, New Concepts and Contermproray Trends, Chapter 15. Hauppauge, USA: Nova Science Publishers, Inc, pp. 235-252.

Gajdzik, B. (2013a). The road of Polish steelworks towards market success - changes after restructuring process. Metalurgija,52(3), pp. 421-424.

Gajdzik, B. (2013b). World Class Manufacturing in metallurgical enterprise. Metalurgija, 52(1), pp.131134.

Gajdzik, B., Sroka, W. (2012). Analytic study of the capital restructuring process in metallurgical enterprises around the World and in Poland. Metalurgija, 2 (51), pp. 265-268.

Krawiec, S. (2014). Adaptacyjne modele wygładzania wykładniczego jako instrumenty prognozowania krótkoterminowego zjawisk ilościowych. Gliwice, Poland: Wydawnictwo Politechniki Śląskiej, pp.12-104.

Manikowski, A., Tarapata, Z. (2002). Prognozowanie i Symulacja Rozwoju Przedsiębiorstw. Warsaw, Poland: Druktur, p.70.

Polish Steel Industry (Yearbook 2017). Katowice, Poland: Polish Steel Association, p. 2.

Rue, L.W., Holland, P.G. (1986). Strategic Management. Concepts and Experiences. New York: McGraw-Hill Inc., pp. 430-432.

World Steel Association. Steel Statistical Yearbook 2017. [online] Available at: www.worldsteel.org/internet-2017/steel-by-topic/statistics/steel-statistical-yearbook-.html (Accessed 5.12.2017). 